\title{
IDENTIFICATION OF THE RESPIRATORY TRACT INFECTION DUE TO METHICILLIN-RESISTANT STAPHYLOCOCCUS AUREUS BY TAQMAN REAL-TIME PCR
}

\author{
Sabah Saad Abdulsahib
}

\begin{abstract}
The methicillin-resistant Staphylococcus aureus (MRSA) is a significant human pathogenic bacterium that is endemic within hospitals around the world. The identification and inspection of MRSA in clinical samples is quite helpful both in advising individual patients about the required care and in tracking these species. The goal of this study was to present a modern, faster, and more accurate diagnostic technique to operate on the real-time duplex PCR applicable to $S$. aureus/MRSA monitoring in Iraqi patients. For this reason, the $S$. aureus-specific nuc gene sequence and the mecA gene sequence were checked simultaneously. To estimate the assay efficiency, a set of six target strains, 34 non-target strains, and 296 clinical specimens were used. The findings obtained from the diagnosis of a total of 296 isolates based on phenotypic characteristics and biochemical tests showed that $146(49.32 \%)$ were classified as individuals with respiratory tract infections of $S$. aureus with a total male to female ratio of 1.47, and 142 isolates demonstrated methicillin resistance. 142 MRSA isolates were investigated in the molecular analysis, all MRSA isolates had positive results for the $n u c$ gene and 138 isolates were positive for the mecA gene. The current real-time PCR assay has $97 \%$ sensitivity, $100 \%$ specificity, and $98 \%$ accuracy.
\end{abstract}

Running title: Identification of the MRSA by real time PCR

Keywords: Staphylococci, antibiotype, antibiotic resistance genes, real-time PCR 


\section{Introduction}

The methicillin-resistant Staphylococcus aureus (MRSA) is a strain of S. aureus that has evolved $\beta$-lactam antibiotic resistance. MRSA can be transmitted by physical contact from person to person and, occasionally, by air. The nasopharynx is the major natural habitat of $S$. aureus, so it is found in about all parts of the body [1]. It has been recognized to be a common pathogen that causes a vast array of disease symptoms, including pneumonia, infection of wound, endocarditis, and bacteremia. The $\beta$-lactam antibiotic is the drug of choice for treatment. The incidence of methicillin-resistant Staphylococcus aureus has gradually increased since methicillin was presented into therapeutic use in 1961, and infections of nosocomial caused by these genotypes are still a global health challenge [2]. Since 1961, successive MRSA disease waves have spread worldwide, to the point that in many countries it is now the most isolated antimicrobial-resistant pathogen. Studies have reported a rise in community-acquired MRSA (CA-MRSA) in patients with or without MRSA infection risk factors over the last few years, which may reflect a shift in epidemiology [3].

There are significant consequences for both the remediation and care of patients infected by $S$. aureus when MRSA strains have been differentiated from several other S. aureus strains [4]. S. aureus is detected in the clinical laboratory by growth characteristics and identification of catalase and coagulase actions. Resistance to methicillin or oxacillin is routinely measured by traditional $S$. aureus susceptibility tests when disk diffusion tests, agar dilution methods have been used in compliance with the guidelines of the national committee of clinical laboratory standards [5]. However, routine susceptibility test takes time to complete. As a phenotypic manifestation of in vitro resistance to methicillin is diverse and most complicated to produce, it is possible to observe false-negative results [6]. Moreover, when commercially obtainable kits are used for monitoring of coagulase, $S$. aureus strains can display a false-negative or non-interpretable result [7].

MRSA strains have been distinguished by a phenotype of beta-lactam resistance; the existence of an extra penicillin-binding protein (PBP) with low-affinity of the subclass PBP2a or hyperproduction of beta-lactamase indicates the key methicillin resistance mechanism. The mecA gene encodes PBP2a, which is located within a mobile genetic variable named the staphylococcal cassette chromosome mec (SCCmec) along with its regulators, mecR1 and mecl $[8,9]$. An extracellular thermostable nuclease encoded by the nuc gene is generated by $S$. aureus, which is one of the most distinctive and effective characteristics that could be used to differentiate $S$. aureus from another Staphylococcus spp. This indicates that a particular marker gene is the nuc gene and PCR is a useful way of detecting this gene in $S$. aureus. Real-time PCR detection of the nuc gene and mecA gene has been characterized as just a quick gold-standard technique to MRSA determination [10].

Reproducibility, speed, and quantitative ability are all advantages of real-time PCR over conventional PCR. Real-time PCR is more sensitive and reproducible, and it can be used in diagnostic routines instead of conventional PCR [11].

A molecular screening test for fast identification of MRSA and a comparison of phenotypic methods with a molecular diagnostic assay was developed and evaluated in this study. The newly designed assay detecting both nuc gene that recognized all staphylococci belonged to $S$. aureus, but not other bacteria, and the mecA gene using duplex real-time PCR.

\section{Materials and Methods \\ Collection of specimens}

A set consisting of 6 target strains ATCC, 34 non-target strains ATCC (Staphylococcus epidermidis $(\mathrm{n}=10)$, Streptococcus agalactiae $(\mathrm{n}=9)$, Clostridium difficile $(\mathrm{n}=8)$, and Enterococcus faecalis $(\mathrm{n}=7))$, and 296 clinical samples were taken from Al-Yarmouk general teaching hospital in Baghdad, over five months, beginning from the first of April to the end of August 2018. Swabs from nares discharge, endotracheal, bronchial aspirates, and sputum were included in the samples. Each patient received only one specimen. Individuals with previously confirmed infection with the MRSA were the preferred chosen. Classical epidemiology data were collected by using standard questionnaires. Information was obtained on name, age, gender, levels of education, country of birth, symptoms, sample type, diagnosis type of test, and present address.

\section{Detection of isolated bacteria}

Each clinical sample was inoculated on mannitol salt agar (MSA) medium (Oxoid, England) plates and incubated for $24 \mathrm{hrs}$ at $37 \mathrm{C}$. The MSA contains $7.5 \%$ $\mathrm{NaCl}$, which, other than Staphylococcus, is inhibitory to the growth of most bacteria. The medium also contains mannitol and phenol red as $\mathrm{pH}$ indicators for the recognition of acid formed by S. aureus fermenting mannitol and distinguishes it from S. epidermidis non-mannitol fermenting, because mannitol-fermenting Staphylococcus create a yellow zone surrounding their growth, and the non-mannitol fermenter does not induce a color change [12].

On a microscope slide, a loop full of a suspected $S$. aureus colony was fixed and then stained with Gram stain to inspect grouping, cell shape, size, and Gram reactivity. Depending on Bergey's manual, $S$. aureus were classified according to the morphological characteristics of culture media and biochemical reactions (Catalase test and Coagulase test). API-staph (Analytic Profile Index System) was followed for further verification. On brain heart infusion agar, bacteria isolates were preserved for a few weeks, the plates were tightly wrapped in parafilm and stored in refrigerator at $4^{\circ} \mathrm{C}$ [13]. 


\section{Methicillin-resistant $S$. aureus detection}

According to CLSI guidelines [14], the Kirby-Bauer procedure would be used to conduct a disk diffusion test, cefoxitin $30 \mu \mathrm{g}$ disc was used as the alternative methicillin to identify resistance to methicillin in S. aureus. All S. aureus isolates already recognized by biochemical and morphological screening were grown on Mueller Hinton agar (Himedia, India) plates with turbidity equal to that of $0.5 \mathrm{McF}$ arland tube containing $1.5 \times 10^{8} \mathrm{cfu}$ per ml. The inverted plates were aerobically incubated for 18 hours at $37^{\circ} \mathrm{C}$ and the diameter of the inhibition zone had been determined. The inhibition zone diameter of $\leq$ $21 \mathrm{~mm}$ had been identified as methicillin-resistant and $\geq 22 \mathrm{~mm}$ was classified as methicillin-sensitive.

\section{Bacterial DNA extraction}

According to the manufacturing instruction of the Wizard Genomic DNA Purification Kit (Promega, USA), the extraction of chromosomal DNA was performed. Three colonies from the 24 hours culture of every strain were transferred into a clean Eppendorf tube and suspend in $480 \mu \mathrm{l}$ 50mM EDTA and $120 \mu$ l of lysozyme. The mix was centrifuged for 2 minutes at $16,000 \times \mathrm{g}$. The cells were lysed with $\mathrm{Nu}-$ clei Lysis solution and RNase solution. The protein was precipitated by adding protein precipitation solution. The DNA was precipitated and rehydrated. The dsDNA concentration was calculated according to manufacturing instructions by the QuantiFluor dsDNA system with the Quantus Fluorometer (Promega, USA).

\section{TaqMan Real-time PCR}

The extracted DNA specimens have been genotyped by TaqMan real-time PCR assays to detected the $S$. aureus species-specific gene, as well as the gene that encoding methicillin antibiotic resistance. The probes fluorescent dyes had been selected to enable genotyping of single-tube PCR, labeled with different fluorescent reporter dyes (VIC-Yellow and FAM-Green) and non-fluorescent Black Hole Quencher 1 (BHQ1) modified. A pair of PCR primers and a probe attach with 5 ' reporter and $3^{\prime}$ quencher molecules are required for each gene; a probe was known as TaqMan.

Possible target regions were identified using GenBank (http:/www.ncbi.nlm.nih.gov/gene/), a sequence specificity for nuc gene was used (GeneBank Accession Version NC 002952.2) and the mecA gene sequence recognition (GeneBank Accession Version NC 021670.1) was utilized to detect methicillin resistance. Primer3web version 4.1.0 (https:/primer3.ut.ee/) was used for the design of primers and probes, and in-silico amplification of PCR (http:/insilico.ehu.es/PCR/index.php?mo=Staphylococcus) was applied to evaluate the assay in silico (Tab. 1).

The lyophilized primers and probe mentioned in Table 1 have been reconstituted with nuclease-free water to make a $100 \mathrm{pmol} / \mu \mathrm{l}$ solution. The required quantity of $25 \mu \mathrm{l}$ SmartCycler tubes has been ready for specimens and controls. The real-time PCR was configured and optimized as follows: in a $25 \mu \mathrm{l}$ tube of SmartCycler reaction, $1 \mu \mathrm{l}$ from $5 \mathrm{pmol} / \mu \mathrm{l}$ from each one of forward and reverse primers and probes (each labeled with different dyes) for the nuc and $m e c A$ genes, $2 \mu$ of DNA was added to $10 \mu \mathrm{l} \mathrm{GoTaq}$ Probe qPCR Master Mix (Promega, USA), and $2 \mu \mathrm{l}$ nuclease-free water (Integrated DNA Technologies, USA). All tubes had been centrifuged and placed in the PCR machine (Cepheid SmartCycler, USA). A thermocycler temperature profile was established as follows: $60^{\circ} \mathrm{C} 30$ secs; $95^{\circ} \mathrm{C} 10$ mins; $95^{\circ} \mathrm{C} 15$ secs and $60^{\circ} \mathrm{C} 1 \mathrm{~min}$ for 40 cycles; $60^{\circ} \mathrm{C} 30$ secs.

Two controls were prepared for each run to prevent false results: negative control, which is prepared by adding $2 \mu \mathrm{l}$ of nuclease-free water instead of DNA to the polymerization reaction components, and positive control, indicated by the reference MRSA DNA sample.

TABLE 1 Primers and probes sequence data applied in current research for real-time PCR resistotyping of $S$. aureus

\begin{tabular}{|c|c|c|c|c|c|}
\hline $\begin{array}{c}\text { Target } \\
\text { gene } \\
\text { symbol }\end{array}$ & Primer and probe sequences $5^{\prime} \rightarrow 3^{\prime}$ & $\begin{array}{l}\text { Nucleotide } \\
\text { positions }\end{array}$ & Aliases & $\begin{array}{c}\text { Product size } \\
\text { (BasePair) }\end{array}$ & Source \\
\hline \multirow{3}{*}{ nuc } & $\begin{array}{c}\text { Forward primer: } \\
\text { GTTGATACACCTGAAACAAAGCA }\end{array}$ & $352-374$ & \multirow{3}{*}{ SAR0847 } & \multirow{3}{*}{156} & \multirow{3}{*}{$\begin{array}{l}\text { Current } \\
\text { study }\end{array}$} \\
\hline & $\begin{array}{c}\text { Reverse primer: } \\
\text { CGCTAAGCCACGTCCATATTTAT }\end{array}$ & $507-485$ & & & \\
\hline & $\begin{array}{c}\text { Probe: } \\
\text { VIC-GGTCCTGAAGCAAGTGCATT-BHQ1 }\end{array}$ & $400-419$ & & & \\
\hline \multirow{3}{*}{ mecA } & $\begin{array}{c}\text { Forward primer: } \\
\text { GGAATGCAGAAAGACCAAAGC }\end{array}$ & $406-426$ & \multirow{3}{*}{$\begin{array}{c}\mathrm{SABB}_{-} \\
\mathrm{RS} 00325\end{array}$} & \multirow{3}{*}{126} & \multirow{3}{*}{$\begin{array}{l}\text { Current } \\
\text { study }\end{array}$} \\
\hline & $\begin{array}{c}\text { Reverse primer: } \\
\text { CTTTGGAACGATGCCTATCTCA }\end{array}$ & 531-510 & & & \\
\hline & $\begin{array}{c}\text { Probe: } \\
\text { FAM-TGGCCAATACAGGAACAGCA-BHQ1 }\end{array}$ & $488-507$ & & & \\
\hline
\end{tabular}




\section{Statistical analysis}

The Statistical Analysis System-SAS [15] program had been used to detect the effect of different factors in study parameters. The Chi-square test was used to significantly compare percentages in this study.

\section{Ethical approval}

The research related to human use has been complied with all the relevant national regulations, institutional policies and in accordance the tenets of the Helsinki Declaration, and has been approved by the University of Technology-Iraq / Department of Biomedical Engineering- Scientific Committee with resolution no. HT/56.

\section{Results}

Isolation and identification of methicillin resistant $S$. aureus

The 296 clinical samples had been screened, 146 $(49.32 \%)$ were identified as S. aureus respiratory tract infection. The data set in figure $\mathbf{1}$ exhibited that the number of infected patients was male 87 $(59.59 \%)$ to female $59(40.41 \%)$, with a total male to female ratio of $1.47(87 / 59)$ with a highly significant difference $(\mathrm{P} \leq 0.01)$. The findings of this study exhibited that 142 isolates showed resistance to methicillin (oxacillin), 84 (59.15\%) in males, and 58 $(40.85 \%)$ in females with a high difference between percentages $(\mathrm{P} \leq 0.01)$.

\section{DNA extraction and concentration}

Extraction of DNA was performed on all $142 \mathrm{~S}$. aureus isolates that were methicillin-resistant, 6 target strains, and 34 non-target strains. The range of DNA concentrations was (41-56) ng/ $\mu$ l. The mean concentration was $47.5 \mathrm{ng} / \mu \mathrm{l}$ and $44 \mathrm{ng} / \mu \mathrm{l}$ was the median. When detected by real-time PCR, all these different DNA concentrations were adequate for effective DNA amplification.

\section{Molecular identification of $S$. aureus by real time PCR}

Extracted DNA specimens from 142 MRSA isolates, 6 target strains, and 34 non-target strains were submitted to real-time PCR molecular diagnosis to identify $S$. aureus identity by amplifying the conserved region of the nuc gene and confirming the result obtained from the methicillin resistance test, using designed gene-specific primers and TaqMan probes. This assay was successful for the qualitative detection. Positive results for the nuc gene were seen in all isolates of MRSA. For the mecA gene, 138 isolates were positive and 4 were negative (Fig. 2).

The current real time PCR assay was distinct with 97\% sensitivity. Specificity testing gave positive results for all six S. aureus/MRSA target strains for nuc gene and mecA gene, and negative results for both genes when tested the 34 isolates of Staphylococcus epidermidis, Streptococcus agalactiae, Clostridium difficile, and Enterococcus faecalis (Tab. 2).

\section{Discussion}

The suspected isolates were able to ferment mannitol on mannitol salt agar and the yellow color was formed because of the generation of acid, Gram staining, and the associated biochemical tests further identified the colonies primarily. Under the microscope, the isolates appeared as Gram-positive coccus-shaped bacteria grouped mainly in clusters.

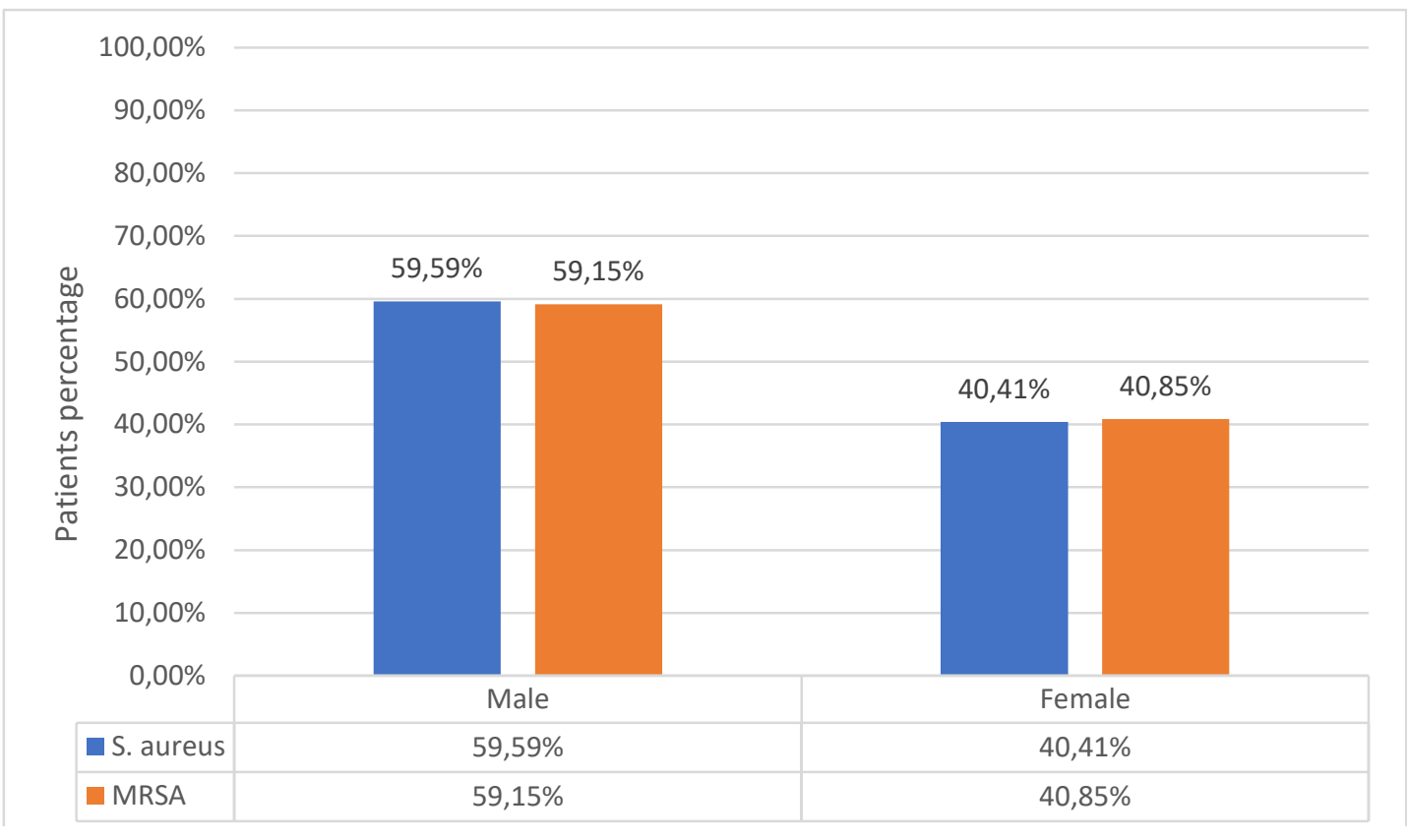

FIGURE 1 A distribution of MRSA among patients 


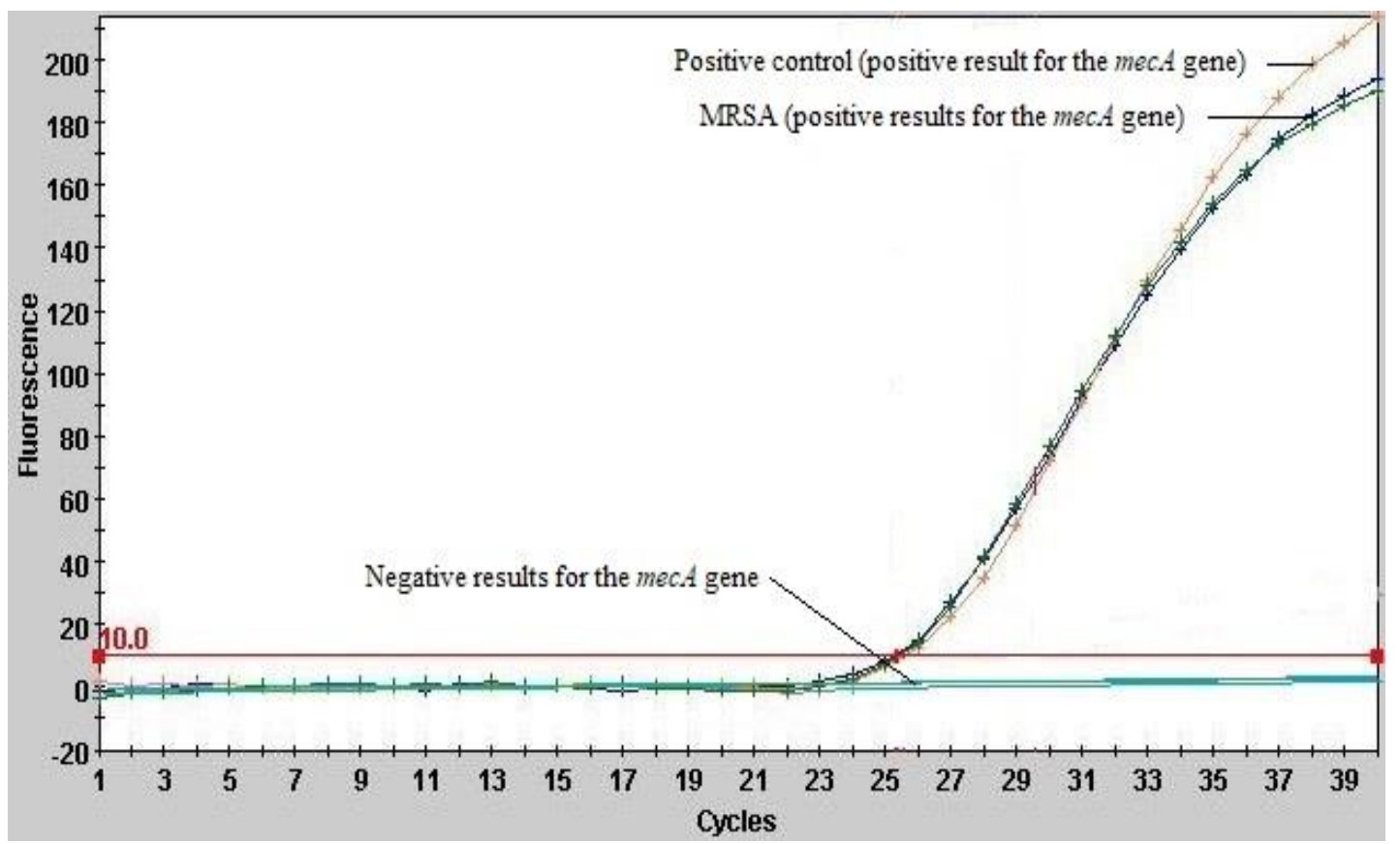

FIGURE 2 The FAM channel of real-time PCR runs for the three specimens, and two controls (negative control and positive control). The progress of the amplification was shown by the three colored curves, one of which was positive control (red curve) and the other was positive results for the mecA gene (MRSA), and the two lines that appeared below the threshold line represent negative results for the $m e c A$ gene and the negative control

TABLE 2 Real-time PCR test sensitivity, specificity, accuracy, and predictive values were measured in 142 MRSA and 34 control subjects

\begin{tabular}{c|c|c|c|c|c|c|c|c}
\hline $\begin{array}{c}\text { True } \\
\text { positive* }\end{array}$ & $\begin{array}{c}\text { False } \\
\text { negative* }\end{array}$ & $\begin{array}{c}\text { True } \\
\text { negative* }\end{array}$ & $\begin{array}{c}\text { False } \\
\text { positive* }\end{array}$ & Sensitivity* & Specificity* & Accuracy* & $\begin{array}{c}\text { Predictive } \\
\text { value of } \\
\text { positive } \\
\text { result* }\end{array}$ & $\begin{array}{c}\text { Predictive } \\
\text { value of } \\
\text { negative } \\
\text { result* }\end{array}$ \\
\hline 138 & 4 & 34 & 0 & $97 \%$ & $100 \%$ & $98 \%$ & $100 \%$ & $89 \%$ \\
\hline$* 16,17]$
\end{tabular}
*[16,17]

They were catalase-positive, differentiating them from the species of Streptococcus, and coagulase-positive, differentiating $S$. aureus from another Staphylococcus spp. Furthermore, a confirmatory test had been conducted using API-staph, a system allowing the suspected isolates to be rapidly identified at the species level. The distribution of MRSA among patients was consistent with previous results reported by Garoy et al.; Vijayamohan and Nair $[4,18]$. S. aureus has become resistant to conventional and new antibiotics in recent years and represents a therapeutic challenge, because of this, the observation of the susceptibility pattern helps assess the possible difficulties of effective therapy [19]. The difference between male and female MRSA susceptibility may be due in part to biological differences, socioeconomic, and cultural factors that lead to gender differences in access to health care. Hand-hygiene behavior varies by sex, men are less obedient and may be predisposed to higher infection rates. An expression of factors of virulence in $S$. aureus has been inhibited by estrogen hormones in a female.
Further evidence on the impact of gender and risk of infection is needed, the reasons for increased MRSA transmission rates in a male are conditions including the possible role of occupation and contact sports [20]. The higher male incidence is poorly understood and requires further research to identify correlated hazard agents.

The result obtained from the extraction of DNA remained in accordance with the study done by Lara et al. [21]. Jaffe et al. [22] found that the median concentration of isolated DNA of $S$. aureus was $78.5 \mathrm{ng} / \mu \mathrm{l}$, the difference between the results of this study and the results obtained from the current study may be explained by the use of larger quantities of bacteria in higher concentrations of DNA and kits used in DNA extraction.

Extracted DNA had been amplified by real time amplification and identified using fluorescent reporter dye probes specific for nuc gene that detected on the Cy3 (Yellow) channel and mecA gene on the FAM (Green) channel (Fig. 2). The assay was constructed to be applicable for the identification of 
MRSA. To keep the general criteria of thermal cycling, the primers had been designed for (57.82-59.01) ${ }^{\circ} \mathrm{C}$ annealing temperature. Via the action of 5' nuclease of the Taq DNA polymerase, the probes fluorescent reporters are released. The interruption between the reporter and the quencher of the fluorescence resonance energy transfer causes the fluorescence reporter to raise the signal. Results were accepted as relevant if positive and negative controls of amplification were passed. Finally, the contrast between the post fluorescence of PCR and the reporter's startup basal fluorescence in given samples allows the studied targets to be genotyped. Post amplification manipulations are not mandatory for the real-time PCR diagnostic methods and are available for automated evaluation of the results. The results of the PCR were analyzed with SmartCycler Dx Version 3.0b software that can be graphically evaluated as points on the axis of the VIC/FAM probe. Experimental testing showed that the PCR had a completely reproducible and efficient amplification for the nuc and mecA genes in one tube. This proposed stable amplification of duplex single-tube without undesirable competitive interactions. $S$. aureus which is phenotypically resistant to methicillin while giving a negative result to $m e c A$ gene inspection may be referred to as having an alternative mechanism for antibiotic resistance instead of this gene, including the modification of penicillin-binding proteins (PBPs) leading to methicillinase or $\beta$-lactamase hyper-production $[23,24]$, this explains why not all $\beta$-lactam resistant isolates have revealed positive results for the mecA gene detection.

In general, compared to the traditional culture methods, the PCR sensitivity and specificity are higher [25]. Within approximately 3 hours, the entire molecular assay was completed. No contamination at any point during the analysis was observed.

\section{Conclusions}

The fast-real time PCR technique identifying MRSA could be provided quick management of the most suitable antibiotic for infections of $S$. aureus. The designed TaqMan probes provide quick and accurate detection of $S$. aureus/MRSA. The technique is rapid, powerful, efficient, laboratory-saving, and reliable for a routine molecular diagnostic based on detection of $S$. aureus/MRSA isolated from clinical samples in a single step.

\section{Acknowledgments}

The Department of Biomedical Engineering, University of Technology, Iraq, approved, sponsored, and supported this research.

\section{Corresponding author}

Sabah Saad Abdulsahib, Biomedical Engineering Department, University of Technology - Iraq, Baghdad, Iraq, e-mail: Sabah.S.Abdulsahib@uotechnology.edu.iq.

\section{Conflict of interest statement}

The author declares they have no conflict of interest.

\section{References}

1. Gurung RR, Maharjan P, Chhetri GG. Antibiotic resistance pattern of Staphylococcus aureus with reference to MRSA isolates from pediatric patients. Future Sci OA. 2020;6(4):FSO464; DOI:10.2144/fsoa-2019-0122.

2. Kumurya AS. Detection of Staphylococcus aureus specific gene and simultaneous confirmation of methicillin resistant Staphylococcus aureus (MRSA) by polymerase chain reaction. Clin Med J. 2015;1(3):88-93.

3. Sadaka SM, El-Ghazzawy EF, Harfoush RA, Meheissen MA. Evaluation of different methods for the rapid diagnosis of methicillin-resistance in Staphylococcus aureus. Afr J Microbiol Res. 2009;3(2):49-55.

4. Garoy EY, Gebreab YB, Achila 00, Tekeste DG, Kesete R, Ghirmay R, Kiflay R, Tesfu T. Methicillin-resistant Staphylococcus aureus (MRSA): prevalence and antimicrobial sensitivity pattern among patients-a multicenter study in Asmara, Eritrea. Can J Infect Dis and Med Microbiol. 2019;2019:8321834; DOI:10.1155/2019/8321834.

5. Loganathan A, Manohar P, Eniyan K, Jayaraj R, Nachimuthu R. Evaluation of various phenotypic methods with genotypic screening for detection of methicillin resistant Staphylococcus aureus. Asian Biomed. 2019;13(6):225-233; DOI:10.1515/abm-2019-0065.

6. Richards V, Tremblay E. Assessment of current methicillin-resistant Staphylococcus aureus screening protocols and outcomes at an academic medical center. Am J Infect Control. 2019;47(8):906-910; DOI:10.1016/j.ajic.2019.02.006.

7. Grisold AJ, Leitner E, Mühlbauer G, Marth E, Kessler HH. Detection of methicillin-resistant Staphylococcus aureus and simultaneous confirmation by automated nucleic acid extraction and real-time PCR. J Clin Microbiol. 2002;40(7):2392-2397, DOI:10.1128/JCM.40.7.2392-2397.2002.

8. Ballhausen B, Kriegeskorte A, Schleimer N, Peters G, Becker K. The mecA homolog mecC confers resistance against -lactams in Staphylococcus aureus irrespective of the genetic strain background. Antimicrob Agents Chemother. 2014;58(7):3791-3798, DOI:10.1128/ AAC.02731-13

9. Pandey N, Cascella M. Beta lactam antibiotics. in: StatPearls. StatPearls Publishing, Treasure Island (FL). 2019.

10. Sahebnasagh R, Saderi H, Owlia P. The Prevalence of resistance to methicillin in Staphylococcus aureus strains isolated from patients by PCR method for detection of $m e c A$ and nuc Genes. Iranian J Publ Health. 2014;43(1):84-92.

11. Paiva-Cavalcanti M, Regis-da-Silva C, Gomes Y. Comparison of real-time PCR and conventional PCR for detection of Leishmania (Leishmania) infantum infection: a mini-review. J Venom Anim Toxins incl Trop Dis. 2010;16(4):537-542.

12. Pumipuntu N, Kulpeanprasit S, Santajit S, Tunyong W, Kong-ngoen T, Hinthong W, Indrawattana N. Screening method for Staphylococcus aureus identification in subclinical bovine mastitis from dairy farms. Vet World. 2017;10:721-726; DOI: 10.14202/vetworld.2017.721-726.

13. Al-Dahbi AM, Al-Mathkhury HJ. Distribution of methicillin resistant Staphylococcus aureus in Iraqi patients and healthcare workers. Iraqi J Sci. 2013;54(2):293-300.

14. Clinical and Laboratory Standards Institute (CLSI). Performance Standards for Antimicrobial Susceptibility Testing. $2^{\text {th }}$ edition. CLSI supplement M100. Wayne, PA. 2019.

15. Statistical Analysis System (SAS). User's guide. Statistical. Version $9.1^{\text {th }}$ ed. SAS. Inst. Inc. Cary. N.C. USA. 2012.

16. Stojanović M, Apostolović M, Stojanović D, Milosevic Z, Toplaovic A, Lakusic V, Golubovic M. Understanding sensitivity, specificity, and predictive values. Vojnosanit Pregl. 2014;71(11):1062-1065; DOI: 10.2298/ vsp1411062s.

17. Skittrall JP, Wilson M, Smielewska AA, Parmar S, Fortune MD, Sparkes D, Curran MD, Zhang $\mathrm{H}$, Jalal $\mathrm{H}$. Specificity and positive predictive value of SARS-Cov-2 nucleic acid amplification testing in a low-prevalence setting. Clin Microbiol Infect. 2021; 27(3):469.e9-469.e15; DOI:10.1016/j. cmi.2020.10.003.

18. Vijayamohan N, Nair SP. A Study of the prevalence of methicillin-resistant Staphylococcus aureus in dermatology inpatients. Indian Dermatol Online J. 2014;5(4):441-445; DOI:10.4103/2229-5178.142488.

19. Guo Y, Song G, Sun M, Wang J, Wang Y. Prevalence and therapies of antibiotic-resistance in Staphylococcus aureus. Front Cell Infect Microbiol. 2020;10(107); DOI:10.3389/fcimb.2020.00107.

20. Humphreys H, Fitzpatick F, Harvey BJ. Gender differences in rates of carriage and bloodstream infection caused by methicillin resistant Staphy lococcus aureus: are they real, do they matter and why? Clin Infect Dis. 2015;61(11):1708-1714; DOI:10.1093/cid/civ576.

21. Lara MO, Lucas TC, kalapothakis E, Thomasini RL, Machado CJ. Comparison of five methods of Extraction of Staphylococcus aureus DNA for molecular detection by PCR. Rev Soc Bras Med Trop. 2018;51(4):528-532; DOI:10.1590/0037-8682-0352-2017.

22. Jaffe RI, Lane JD, Albury SV, Niemeyer DM. Rapid extraction from and direct identification in clinical samples of methicillin-resistant 
staphylococci using the PCR. J Clin Microbiol. 2000;38(9):3407-3412; DOI:10.1128/JCM.38.9.3407-3412.2000.

23. Cabrera R, Fernández-Barat L, Motos A, López-Aladid R, Vázquez $\mathrm{N}$, Panigada M, Álvarez-Lerma F, López Y, Muñoz L, Castro P, Vila J, Torres A. Molecular characterization of methicillin resistant Staphylococcus aureus clinical strains from the endotracheal tubes of patients with nosocomial pneumonia. Antimicrob Resist Infect Control. 2020;9(43); DOI:10.1186/s13756-020-0679-Z

24. Caires CSA, Silva CM, Lima AR, Alves LM, Lima THN, Rodrigues ACS, Chang MR, Oliveira SL, Whitby C, Nascimento VA, Caires ARL. Photodynamic inactivation of methicillin-resistant Staphylococcus aureus by a natural food colorant (E-141ii). Molecules. 2020;25(19); DOI:10.3390/ molecules25194464.

25. Mutonga DM, Mureithi MW, Ngugi NN, Otieno FCF. Bacterial isolation and antibiotic susceptibility from diabetic foot ulcers in Kenya using microbiological tests and comparison with RT-PCR in detection of $S$. aureus and MRSA. BMC Res Notes. 2019;12:244; DOI:10.1186/ s13104-019-4278-0. 